\title{
A CONSTITUIÇÃO DE UMA QUESTÃO SOCIOCIENTÍFICA EM UM GRUPO DE PROFESSORES: UM PROCESSO POLIFÔNICO DE DESVELAMENTO DA REALIDADE CONCRETA
}

\author{
THE ESTABLISHMENT OF A SOCIO-SCIENTIFIC ISSUE IN A GROUP OF \\ TEACHERS: A POLYPHONIC PROCESS OF UNVEILING THE \\ CONCRETE REALITY
}

Paulo Gabriel Franco dos Santos ${ }^{1}$ Washington Luiz Pacheco de Carvalho ${ }^{2}$

\section{RESUMO}

Este artigo apresenta parte de uma pesquisa mais ampla e busca elucidar o processo de constituição de uma Questão Sociocientífica em um grupo de professores de uma Escola Pública. Partindo da premissa que uma Questão Sociocientífica deve agregar os envolvidos no processo educacional em situações de diálogo, argumentação e construção de posicionamento, entendemos que o reconhecimento da controvérsia ou da legitimidade do tema no contexto em questão é fundamental para alcançar os objetivos pretendidos. Sendo assim, partindo de subsídios da Teoria Crítica da Sociedade, caracterizamos o processo de constituição de uma Questão Sociocientífica entre professores como um exercício de desvelamento da realidade concreta, elencando aspectos problemáticos, controversos e passíveis de crítica da Ciência e da Tecnologia. Desse modo, a Questão Sociocientífica é elencada no grupo a partir do momento em que se estabelece um diálogo polifônico em que todos os participantes se posicionam, reconhecem a fertilidade do tema para o contexto educacional pretendido e conseguem falar dele com propriedade.

Palavras-chave: Questões sociocientíficas; Formação do sujeito; Grupo de professores.

\begin{abstract}
This article presents part of a broader research and seeks to elucidate the process of setting up a Socio-scientific Issue in a group of teachers at a public school. Assuming that a Socioscientific Issue must aggregate those involved in the educational process in situations of dialogue, argumentation and construction of a positioning, we understand that the recognition of the controversy or of the legitimacy of the theme in the context at stake is crucial to achieving the desired goals. Thus, starting from subsidies from the Critical Theory of Society, we characterize the process of setting up a Socio-scientific Issue among teachers as an exercise of unveiling the concrete reality, listing problematic, controversial and open to criticism aspects of Science and Technology. Thus, the Socio-scientific Issue is listed out in the group as soon as it is established a polyphonic dialogue where all participants stand, recognize the fertility of the themefor the intendededucational context and can speak of it with propriety.

\footnotetext{
${ }^{1}$ Doutorando pelo Programa de Pós-Graduação em Educação para a Ciência - Faculdade de Ciências - UNESP - Campus Bauru. e-mail: paulogabriel22@yahoo.com.br

${ }^{2}$ Departamento de Física e Química - UNESP - Campus de Ilha Solteira / Programa de Pós-Graduação em Educação para a Ciência - Faculdade de Ciências - UNESP - CampusBauru. e-mail: wascar@ dfq.feis.unesp.br

AMAZÔNIA - Revista de Educação em Ciências e Matemáticas V.9 - no 17 - jul. 2012/dez. 2012, p.1-26.
} 
Key words: Socio-scientific issues; Formation of the subject; Group of teachers.

\section{INTRODUÇÃO}

A Educação Científica, na sociedade contemporânea, é desafiada a lidar com a avalanche de informações e demais produções advindas do contexto da Ciência e da Tecnologia. A natureza dos aparatos tecnológicos, os rumos da pesquisa científica, a popularização da ciência, o (des) serviço da divulgação da ciência e mais uma série de elementos deste campo implicam em ponderações no campo da política, ética, economia, cultura, valores, além dos conhecimentos científicos específicos.

A perspectiva CTSA, que se ocupa das relações entre Ciência, Tecnologia, Sociedade e Ambiente, prevê o trato com os desafios que se apresentam na contemporaneidade. Pedretti et al.(2008) apresentam algumas características fundamentais da Educação CTSA. Nomeadamente:

\footnotetext{
Educação CTSA, fundamentalmente, representa uma visão pós-positivista da ciência e do ensino de ciência que enfatiza: transformação (por meio da ação sociopolítica); tomada de decisão; interdisciplinaridade; incerteza; múltiplas soluções; a ligação da ciência e ética; e o professor como facilitador e guia (PEDRETTI et al., 2008, p. 955, tradução nossa).
}

Há de se destacar, assim, os desafios para a efetivação de um modelo educacional com esse mote. Envolver-se em um campo vasto, dinâmico e plural, como o da Educação CTSA, requer um movimento contrário ao tradicionalmente instaurado na escola básica, no ensino superior, bem como um olhar crítico na ciência como é desenvolvida e divulgada. Na escola básica, por exemplo, uma aula planejada com debates, discussões, explanação de temas científicos da atualidade geralmente é considerada "perda de tempo" ou “enrolação do professor". O contrato com a tradição é firmado em nível curricular e influencia a compreensão de alunos, professores, pais e gestores sobre o que e como ensinar. Pedretti et al.(2008) apresentam estes atravanques como problemas de identidade e ideologia dos professores, formados em modelos positivistas de ciência e ensino de ciência.

Nesse contexto, apresenta-se aqui parte de uma pesquisa mais ampla (SANTOS, 2013), que procurou envolver professores de uma escola pública, do interior do Estado de Mato Grosso do Sul, na construção de um grupo de estudos (Pequeno Grupo de Pesquisa), cuja tônica foi a discussão de Questões Sociocientíficas e o planejamento e adequação para a efetivação no plano escolar, entendo o tratamento de Questões Sociocientíficas como possibilidade de pôr em prática os pressupostos de uma Educação 
CTSA. A escolha de uma questão coerente com a realidade dos envolvidos, contextualizada, potencialmente fértil para gerar situações de problematização e argumentação demandou um processo longo de negociações, posicionamentos, exercício de desvelar a realidade concreta dos sujeitos que seriam submetidos ao processo educacional, ou seja, professores, alunos e comunidade.

\section{AS QUESTÕES SOCIOCIENTÍFICAS E A EDUCAÇÃO CIENTÍFICA EM UM PROCESSO DE DESVELAMENTO DA REALIDADE CONCRETA}

Em um mundo em rápida transformação e fortemente baseado em Ciência e Tecnologia, urge a necessidade da formação de sujeitos que sejam capazes de transitar nas mais diversas áreas do conhecimento. Uma educação científica, tal como apresentada por Ratcliffe e Grace (2003), busca formar cidadãos que compreendam os processos das ciências, a natureza do conhecimento científico e das produções tecnológicas, bem como que sejam capazes de se posicionar e de argumentar em situações complexas envolvendo temas científicos, dando especial atenção aos aspectos de valores humanos, raciocínio ético, a fim de instaurar embates democráticos para o processamento de temas controversos.

Segundo Reis (2004):

A avaliação das consequências e a correcção dos eventuais problemas resultantes do crescimento científico e tecnológico requer: a) um enquadramento de conhecimentos científicos indispensáveis à apropriação de conhecimentos mais pormenorizados sobre as questões em causa; b) conhecimentos metacientíficos sobre a natureza, as potencialidades e os limites da ciência; c) capacidades de pensamento crítico, tomada de decisões e resolução de problemas; d) atitudes e valores úteis à avaliação das dimensões ética e moral da ciência e da tecnologia; e e) vontade e confiança para lidarem com assuntos científicos do seu interesse (REIS, 2004, p. 51).

A título de exemplificação, tomemos alguns casos: o desenvolvimento da biotecnologia e a utilização de células-tronco embrionárias humanas; o uso de pesticidas em lavouras, bem como o de sementes transgênicas; uso de certos produtos químicos na indústria da beleza, na alimentícia e na farmacêutica; as pesquisas em materiais poliméricos e a popularização do uso dos plásticos; as matrizes energéticas e os recursos naturais demandados. Em todos os casos, para o sujeito se posicionar, serão mobilizados conhecimentos que vão além dos científicos, pois são questões sociais complexas que envolvem variáveis econômicas, culturais, políticas, éticas que não devem ser excluídas em um processo de decisões e construção de posicionamento. Os temas citados têm potencial de se converterem em Questões Sociocientíficas e serem trabalhados em sala de aula. 
Para Ratcliffe e Grace (2003), as Questões Sociocientíficas são aquelas que têm uma base na ciência e um impacto potencialmente grande na sociedade. Os mesmos autores apresentam alguns aspectos do que chamam de natureza das questões sociocientíficas, que tenham uma base nas ciências, que envolvam formação de opinião e escolhas, que sejam noticiadas pela mídia, que lidem com as informações incompletas da ciência, que sejam locais ou globais, que envolvam análises de custo-benefício, de risco e de valores, que envolvam considerações sobre o desenvolvimento sustentável e que envolvam o raciocínio ético.

As questões sociocientíficas surgem, assim, como possibilidade de efetivação de uma Educação para a Ciência para a cidadania, a participação pública, o posicionamento crítico, planejamentos e projeções de ações social, democrática e transformadora (HILÁRIO; REIS, 2009), (RATCLIFFE; GRACE，2003), (ZEIDLER; KEEFER，2003), (HODSON, 2011).

[...]a proposta de trabalho com as questões sociocientíficas no ensino de ciências, tem como preceito básico os sujeitos como responsáveis por suas ações. Este enfoque procura abandonar o pensamento facilitado pelas informações ideológicas prontas e se baseia na negação do pensamento previamente formado. Desta forma, o que seria tido como conhecimento pronto, como resultado irrefutável e baseado na evidência científica, agora é posto à prova, segundo as perspectivas de diferentes grupos defensores de diferentes argumentos (LOPES, 2010, p. 66).

Questões de natureza subjetiva são afetas às escolhas em nível individual e coletivo, como a capacidade de julgamento, ponderação moral e ética e raciocínio informal, e são bastante caras na literatura sobre QSC (GUIMARÃES, 2011) (RATCLIFFE; GRACE, 2003) (ZEIDLER; KEEFER, 2003) (GRAY; BRYCE, 2006). O raciocínio informal envolve “inferências, justificação de crenças, explicações de observações” é não é construído a partir de uma lógica formal, ou seja, não se define como um argumento constituído por duas premissas e uma conclusão, mas é contextual e leva em conta a solidez do argumento (GUIMARÃES, 2011). Assim, o embate coletivo de posicionamentos, o exercício argumentativo, a partir de uma lógica informal, as tensões de valores e crenças e a relativização de verdades absolutas podem conduzir a um desenvolvimento de questões morais e éticas.

Khishfe (2012) propõe que, para a formação de uma sociedade democrática, é necessário que haja cidadãos participativos que tomam decisões e que o Ensino de Ciências é potencialmente capaz de proporcionar este tipo de formação para os sujeitos.

Por outro lado, Pedretti et al. (2008) apontam algumas dificuldades apresentadas para a efetivação de um trabalho com QSC no contexto escolar: 
Muitos professores temem que a extensa cobertura das questões sociocientíficas desvalorize o currículo, aliene os estudantes de ciências tradicionais e põe em risco seu próprio status como guardiões do conhecimento científico (Hughes 2000). Normalmente, o professor está no controle e os alunos participam em tipos fechados de repetição ou verificação de investigação com pouco espaço para a imaginação, a criatividade ou uma abordagem de caráter aberto (PEDRETTI et al., 2008, p. 943, tradução nossa).

Ainda assim, entendemos que o professor é o principal responsável por estabelecer o elo entre a cultura científica e a cultura do sujeito, de forma a não sobrepujar uma em detrimento da outra. Assim, é no contexto de formação escolar que se amplia a possibilidade de se compreender os modos como a ciência se constrói. Dessa forma, tornar nítidas as suas intencionalidades, caminhos e produtos, bem como reconhecê-la como parte da cultura humana, como um constructo social determinado pela história e pelo contexto, e também como um empreendimento passível de falhas, promotor de riscos ao ambiente e fortemente conectado com aspectos financeiros e políticos.

Cabe aos professores estabelecer a ponte entre a cultura associada à comunidade de cientistas e o resto da sociedade através da iniciação dos alunos em determinados aspectos da cultura científica (GALVÃO, REIS e FREIRE, 2011, p. 508).

Ao mesmo tempo em que discutimos a potencialidade das QSC no ensino de ciências, Adorno e Horkheimer (1985) apresentam que "o esclarecimento tem perseguido sempre o objetivo de livrar os homens do medo de investi-los da posição de senhores" (p.19). O esclarecimento é entendido como um processo de desencantamento do mundo. O que encanta na modernidade são os mitos, as formas fetichistas que se apresentam e conduzem o homem à uniformização das vontades. Quando, porém, manifesta-se a coação sobre a natureza dominada, como a ciência o faz de forma autêntica, o esclarecimento se converte em dominação e se coloca a serviço do presente convertendo-se na total mistificação das massas (ADORNO; HORKHEIMER, 1985).

Ocupar-se das situações reais da influência da ciência e da tecnologia na cultura, das contradições sociais, das relações de opressão e violência contra o ser humano, das manifestações de autoritarismo, dominação e hierarquização, bem como os discursos atrelados a elas, converte-se na nossa compreensão de desvelamento da realidade concreta. $\mathrm{E}$ um movimento de constatação das determinações sociais que ordena a vida das pessoas, ou seja, reconhecer-se em plena vivência na semicultura, e buscar, por meio da negação e do resgate da razão emancipatória, os meios de resistência e transformação.

A educação, para ser efetiva, é crítica da semiformação real, resistência na sociedade material presente aos limites que nesta se impõem à vida no 'plano' de sua produção efetiva. A emancipação é elemento central da educação, mas, para ser 
real e efetiva, há que ser tematizada na heteronomia (MAAR, 2003, p. 473, grifos do autor).

O desvelamento da realidade concreta, por fim, deve conduzir à inquietação, ao anseio de mudança, ao espírito da crítica. A compreensão, no nosso exemplo, da Natureza da Ciência e da Tecnologia é parte ínfima do desvelamento da realidade concreta, porém tem a sua importância. Reconhecer como a ciência funciona, quais são os seus mecanismos de validação de teorias, apropriação de dados e informações sobre fenômenos da natureza, bem como a quem essa ciência serve e a quais saberes tais técnicas estão atreladas faz parte de um programa que pretende desencantar a ciência e denunciar as mazelas provenientes do seu fazer. Trata-se, por fim, de um processo de reconhecimento do sujeito na sua história, no seu tempo, espaço, suas lutas e condições de opressão, suas relações com os meios de produção da ciência e da tecnologia na sociedade.

Portanto, os contextos de discussões sobre aspectos da educação científica devem ser repensados de modo a privilegiar a formação epistemológica (HODSON, 1988) (DÉSAUTELS; LARROCHELLE, 1997,1998) a fim de que os professores possam fazer a ponte entre os aspectos da cultura científica e a cultura do sujeito, fundamentar as situações de argumentação sobre questões controversas, envolvendo ciência e tecnologia e romper com ciclo clássico e vicioso de reproduzir o tipo de ensino conforme as suas experiências como aprendizes.

\section{PROCEDIMENTOS METODOLÓGICOS: A NATUREZA DO PROCESSO}

De natureza qualitativa (BOGDAN; BIKLEN, 1994), o processo de constituição e consolidação de um Pequeno Grupo de Pesquisa, constituído por professores da escola e da universidade, contou com diferentes fases, sendo importante ressaltar que a iniciativa e idealização deste grupo foram possíveis graças ao Projeto Observatório da Educação com foco em Matemática e Iniciação às Ciências, do qual a UNESP (Ilha Solteira SP) faz parte e é de onde falamos:

Fase embrionária: Contou com a negociação entre o pesquisador e o professor (que se tornaria o coordenador e articulador do PGP) sobre questões práticas da construção do grupo, proposta de estudo e trabalho, afinação dos discursos advindos da Universidade e da Escola; 
Gênese do PGP: Trata-se da entrada na Escola, as primeiras reuniões com os professores interessados em participar espontaneamente, esclarecimentos sobre objetivos do Projeto e vontades e anseios apresentados pelos professores; primeiras leituras sobre QSC;

Desenvolvimento do PGP: Engloba a maior parte do processo do PGP decorrido no ano de 2012. Inclui o processo de constituição da QSC do grupo, discussões sobre a Natureza da Ciência e da Tecnologia, a constante significação do processo, criações dentro do grupo para dar visibilidade dentro da escola. Trata-se da fase na qual a horizontalidade das relações se aproxima de um cenário ideal, os sujeitos começam a sofisticar seus diálogos sobre o grupo e as teorias estudadas, bem como se reconhecer dentro do processo.

Desfechos do PGP: Inclui ações práticas dos professores com os alunos, com base na QSC do grupo e conforme interesse formativo de cada um.

As reuniões decorreram no ano de 2012, contaram principalmente com três professores da escola (Professor de Física - Joaquim -, Professor de Química - João -, Professora de História - Maria) e o pesquisador (representante da universidade), além de participações esporádicas de professores da universidade (Prof. Univ.2) e um graduando em Física. A periodicidade dos encontros foi semanal, com duração de aproximadamente 2 horas cada uma. O recorte tratado nesse artigo inclui o processo de constituição da QSC do grupo, já na fase do desenvolvimento do PGP. A pesquisa procura cuidar da natureza processo instaurado, da construção coletiva de conhecimentos, do envolvimento dos professores em um contexto de estudos e teorização que resiste ao engessamento clássico observado na vida escolar.

\section{TRATAMENTO DAS INFORMAÇÕES E DISCUSSÃO DOS RESULTADOS}

As informações recortadas são apresentadas e acompanhadas de um trato descritivo para expressar com detalhes os elementos evidenciados, os aspectos valorizados, bem como a qualidade da exploração dos elementos da realidade dos envolvidos. Ressaltamos que as falas apresentadas aqui não correspondem à totalidade da pesquisa que realizamos em nível de mestrado, como já evidenciado.

Com base em Bardin (2009), optou-se pela análise de conteúdo e, mais especificamente, análise temática. Para tanto, o exercício analítico inicia-se no preparo das comunicações a serem analisadas, a constituição do corpus de informações, os recortes, a seleção do tema, as sínteses e inferências a partir delas. 
O tema em questão, o Processo de Constituição de um QSC, inclui desde as propostas iniciais de QSC para o trabalho no grupo até a escolha da QSC definitiva. Trata-se da análise das propostas, da aceitação, dos argumentos acerca da fertilidade da questão, da explosão de possibilidades que surgem com a exploração do tema e necessidades de aprofundamento.

As comunicações selecionadas para a compreensão deste tema são os episódios, contendo as falas e uma nota de reunião feita coletivamente. A análise englobada por este tema baseia-se na interpretação da comunicação que se dá pela descrição do episódio, seleção dos elementos evidenciados e qualificação do tema.

\section{Episódio 1: Primeiras possibilidades e a Questão do uso do fone de ouvido entre os jovens}

Pesquisador: O Prof. Joaquim propôs, e em conversa com ele a gente pensou em elaborar tipo um projeto piloto para passar pra esses alunos, pra gente saber com o que de Ciência e Tecnologia eles estão mais familiarizados para aí a gente começar a projetar as nossas ações. Entendeu? Tipo um projeto primeiro. Primeira etapa, digamos. Sabe... passando um questionário... Porque, de repente, a vivência é muito rápida, a convivência é muito pequena. Claro que uma coisa em comum todos têm: vivem em Paranaíba. De repente isso teria uma facilidade em enxergar questões locais. Mas de repente tem questões muito mais locais que a gente não está percebendo. Por exemplo, eu fui conversar com o meu orientador sobre essa ideia do Joaquim e ele falou "Olha, pode surgir, por exemplo, o uso do fone de ouvido". Tem MP5, 6, 7, 8... 15... Celular e fones de ouvido de qualidade muito ruim. Ou então as pessoas ouvem isso muito alto. Isso daí pode ser uma Questão Sociocientífica muito boa. Certo? Isso pode ser uma questão Sociocientífica que a gente vai poder estudar muita coisa em cima dela. E aí, vai da nossa criatividade sobre como a gente vai aprofundar nisso. Como, por exemplo, a gente vai atacar o problema da surdez precoce, a questão das ondas, ver onde a química entra nisso aí, estruturar uma sequência didática de artes que esteja articulada com a questão do som. Por exemplo, aqueles desenhos que formam em cima de caixas de som com areia... Enfim, vai da criatividade de cada um no decorrer do processo. Mas é uma ideia [o questionário] que eu lançando agora, que a gente [pesquisador e Prof. Joaquim] teve junto.

O pesquisador, em um exercício de iniciar processo de constituição da Questão Sociocientífica, de desvelamento da realidade e dos problemas, começa a trazer temas que podem ser potenciais para a constituição de QSC. A problemática do fone de ouvido surge de articulações no contexto da universidade e vai para o grupo como proposta, como um input para se começar a falar de questões problemáticas com potencial de trabalho na escola como QSC. 
A temática do uso do fone de ouvido entre os jovens seria plenamente justificável por se tratar de um artefato tecnológico de uso disseminado e, comumente, negligente. A variedade de produtos desta natureza no mercado, influenciada pela demanda, implica na difusão de produtos de qualidades também variadas. Resgatando os elementos afetos a uma Questão Sociocientífica, conforme Ratcliffe e Grace (2003), temos nessa temática a questão de custo-benefício, compreensão de riscos, envolve a formação de opinião, por estar fortemente presente na vida dos educandos e, principalmente, tem base na ciência e na tecnologia. As possibilidades de trabalho são amplas e agregam também questões de valores de um grupo social, comportamento, pluralidade de posicionamento, requer compreensão de elementos da ciência para fazer escolhas e tomar decisões, o que está alinhado com os elementos para uma tomada de decisão bem fundamentada (KHISHFE, 2012).

Mesmo com a fertilidade do tema, a proposta entrou na dinâmica do grupo precocemente, com o intuito não de definir uma questão a ser trabalhada, mas disparar processos reflexivos sobre temas dessa natureza e argumentação entre os professores sobre a sua validade. Caso o grupo esgotasse a discussão sobre o tema e optasse por ele, após um bom trânsito teórico e o surgimento de possibilidade de criação, poderia sim se tornar a questão do grupo. O que não ocorreu. Isto evidencia uma discussão importante para o tratamento de QSC na escola básica, a de que estes temas devem surgir do grupo, de forma a fazerem parte da vida dos envolvidos e não ser levadas como um produto pronto à escola.

Elementos evidenciados: A proposta advém do contexto da universidade para o grupo na escola e conta com pouca agregação dos sujeitos envolvidos. Não há multiplicidade de vozes dos participantes e a questão é deixada como uma possibilidade.

Episódio 2: Primeira ideia sobre formol diante da necessidade de contextualização no ensino

Pesquisador: Por exemplo, João, na química. Qual a possibilidade de formar um cidadão crítico ensinando química?

João: Ele tem que conhecer... Ter um amplo conhecimento da química.

Pesquisador: Da química...

João: É. De todo o conteúdo... Se ele não tiver um conhecimento, ele não vai poder dar opinião sobre os assuntos. 
Pesquisador: Certo. E quando ele sair, por exemplo, do portão da escola, que aí tem um mundo ao redor dele, um monte de coisa, que não é fragmentada igual dentro da escola. Onde esse conhecimento, que você está falando, amplo de química, vai ajudar ele a ser no mundo fora da escola? Entendeu? O que saber que o oxigênio tem tantos elétrons na última camada vai contribuir para a formação do cidadão?

Joaquim: Eu estava até discutindo na sexta passada... Não veio quase nenhum aluno no $1^{\circ} \mathrm{C}$, veio só o [nome do aluno] e eu estava falando com ele: "Ah, por que você não vem nas aulas... ou vem pouco aluno... foram desistindo?" Aí ele contou que o que ele via aqui na escola, pra ele não servia, não ia usar lá fora, no serviço dele, na vida dele.

João: Por exemplo, o uso do formol. Então a química, ela vai ensinar formol. Então, por exemplo, ela [a aluna] vai ter um conhecimento lá fora, ela vai ver que uma dose alta de formol vai prejudicar, por exemplo, dar câncer... vários problemas para a saúde.

Pesquisador: Isso. Foi ótimo você levantar a questão do formol. Onde que é mais usado o formol, atualmente?

João: No cabelo.

Pesquisador: Exatamente. Exatamente. Isso é uma coisa muito importante... Essa contextualização.

João: Por exemplo, se ele tem um conhecimento, ele vai chegar na cabeleireira: “quantos ml?”, “qual a porcentagem de formol nesse produto?”. Ele vai ter um conhecimento pra própria saúde dele.

O episódio 2 expressa uma questão muito importante nos embates sobre Ensino de Ciência, Educação CTSA e Questões Sociocientíficas: a questão do conteúdo. O professor João, a princípio, recorre ao "amplo conhecimento de química", como possibilidade de formar cidadão por meio do ensino. O pesquisador entendendo "amplo conhecimento de química" como uma vastidão de conteúdos específicos da área de química, sustenta a provocação inserindo uma reflexão sobre a validade desses conhecimentos na vida ordinária do educando. É perceptível que o pesquisador extrapola na problematização quando provoca uma tensão sobre a validade do ensino de estrutura da matéria (átomos e partículas elementares), que é um conteúdo clássico da disciplina de Química, mas isso não perde a tônica do questionamento sobre os conhecimentos necessários para uma formação cidadã e participação pública. Ratcliffe e Grace (2003) apontam que um dos eixos com os quais as Questões Sociocientíficas estão concatenadas é a educação científica, que prevê o ensino de conceitos científicos-chave, juntamente com outros conhecimentos, a Natureza da Ciência, para a promoção de uma educação cidadã. Khishfe (2012), por sua vez, apresenta que um dos elementos para uma tomada de decisão sobre ciência e tecnologia, bem fundamentada, é examinar os conhecimentos científicos relevantes. 
O professor Joaquim sustenta a provocação do pesquisador, inserindo outros elementos, provenientes de uma experiência em sala de aula, para falar sobre a aproximação do que se ensina em sala de aula com a vida dos sujeitos. O professor João, compreendendo a natureza da provocação e mobilizando conhecimentos provenientes de sua formação, insere na pauta a possibilidade do tema "o uso do formol" como frutífero, que atendia às provocações a ele dirigidas. Justifica a validade do tema exemplificando contextos de mobilização do conhecimento científico na vida cotidiana, que são contextos de posicionamentos e de participação social tão desejados em uma educação cidadã e como fruto do trabalho com Questões Sociocientíficas.

Elementos evidenciados: A proposta advém do contexto do grupo e conta com bom posicionamento sobre a fertilidade do tema. Os posicionamentos são provocados pela necessidade apresentada no grupo de ligação entre o que se aprende na escola e a vida cotidiana para uma formação cidadã. A questão é deixada como uma possibilidade.

\section{Episódio 3: Continuação da explanação sobre o uso do Formol como Questão Sociocientífica}

João: O formol, por exemplo, antigamente você podia usar, agora não...

Pesquisador: O éter?

João: Não o formol, do cabelo...

Pesquisador: Ah, do cabelo. Era isso que eu queria lembrar.

João: Por exemplo, acho que foi em 2008 que a ANVISA [Agência Nacional de Vigilância Sanitária] proibiu. Se não me engano, 2008 ou 2009. Proibiu e aí só pode ter de 0,2\% de formol no alisante.

Joaquim: Por quê? O formol provoca o quê?

João: Irritação, câncer, futuramente, deixa a pele vermelha... Coceira.

Pesquisador: Então vamos colocar aqui o que gente... É... Amassado de latas, fones de ouvido vamos considerar também... O outro? Formol... Uso do formol em cosméticos, né?

João: No alisante capilar..

Pesquisador: É. Essa questão do formol realmente é importante.

No episódio 3, o tema do uso do formol surge novamente, dessa vez com mais elementos no posicionamento do professor propositor, o professor João. Entre a primeira proposta e essa, surgiu outra bastante fértil que será analisada nos próximos dois episódios. 
Nesse episodio, são mobilizados conhecimentos científicos sobre o uso do formol, questão de legislação nacional, bem como fatores de risco à saúde humana. Com esses elementos, a questão ganha mais corpo e a argumentação sobre a fertilidade dela se torna mais convincente. O diálogo se dá entre o professor João e o pesquisador, que reconhece a importância do tema no contexto.

\section{Elementos evidenciados}

A questão já conta com um posicionamento mais enriquecido sobre a fertilidade do tema, incluindo conhecimentos científicos, legislação e questões de risco. A questão é deixada como uma possibilidade.

Episódio 4: A possibilidade do problema do amassado de latas (embalagens metálicas de armazenamento de alimentos) como uma Questão Sociocientífica

João: a latinha quando ela está amassada... Você vai comprar a ervilha, por exemplo, um milho... se ela tiver amassada, nem compra ela! Porque você pode ver que por dentro dela é um verniz que é passado. Se amassar ela, o verniz, ai entra em contato com o ferro [provavelmente o líquido] e ele vai oxidar.

Pesquisador: Ela vai abrir, você fala, o verniz...?

João: Não, ele vai liberar íons. Por exemplo, o verniz abre e ele vai entrar em contato diretamente...

Pesquisador: O líquido?

João: ... Aquele líquido com a lata. A lata vai oxidar e libera íons e aí prejudica a saúde. Por exemplo, vai ter uma alta concentração de ferro que futuramente vai complicar... vai ter algum sintoma futuramente, no organismo da gente... O alumínio mesmo, por exemplo... Então têm várias...

Joaquim: Engraçado, isso poderia ser uma Questão Sociocientífica, né? De o aluno em sala de aula compreender a química, compreender os conceitos químicos e, quando ele for ao mercado, no dia a dia, ele ver isso, ele identificar, né? "Ah, eu não vou comprar esse enlatado porque eu vi na aula de química isso". Interessante isso.

Pesquisador: Exatamente! Eu estou rodeando pra chegar nisso.

No episódio 4, o tema que ganha destaque é o "amassado das latas", das embalagens metálicas que contêm alimentos. O professor João traz à tona a questão dos problemas acarretados pelos amassados nas embalagens metálicas, mobilizando conhecimentos de química e o professor Joaquim, por sua vez, reconhece a fertilidade do tema como uma 
Questão Sociocientífica. Ao reconhecer a temática como uma QSC, o professor Joaquim justifica seu posicionamento, apresentando as possibilidades de tomada de decisão na vida cotidiana fundamentada com conhecimentos sobre a questão, argumentando que o conhecimento aprendido nas aulas de química poderia orientar os sujeitos a fazer escolhas cientes na hora da compra, ponderando questões de risco.

Novamente surge o elemento "construção de posicionamento" para sustentar a validade de um trabalho com determinada questão. Considerando este um elemento caro a uma Educação Científica com foco nas Questões Sociocientíficas, o fato de os professores se valerem deste argumento representa certo trânsito teórico e compreensões mais consolidadas sobre a teoria em questão.

\section{Elementos evidenciados}

O episódio apresenta bom posicionamento sobre a fertilidade do tema, incluindo conhecimentos teóricos sobre o tratamento das Questões Sociocientíficas e conhecimentos científicos sobre a problemática em questão. A questão é deixada como uma possibilidade.

Episódio 5:Continuação da exploração do tema “Amassado das latas”

Pesquisador: Sabe uma coisa que eu achei bacana da reunião passada? A questão do amassado de latas. Achei curioso aquilo. Até que eu e o Joaquim comentamos, né Joaquim? Essa questão do amassado das latas é bem interessante.

João: Dá pra estudar em eletrólise...

Pesquisador: Como que é?

João: Eletrólise... De pilhas. Qual oxidou, qual reduziu... Oxirredução.

Pesquisador: Ah, a questão da oxidação da lata, você está falando...

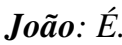

Pesquisador: Entendi.

Joaquim: Tem um dia que eu dou aula aqui à noite, de química. Eu fiz essa pergunta... Eu perguntei assim: "Mas você não vai comprar o produto só pelo amassado? E se inferioriza muito o produto... o valor do produto?”. Aí eu fui perguntando...

Pesquisador: Olha que bacana... 
Joaquim: Aí eles ficaram com dúvida. Aí eu falei assim: "Eu que tenho conhecimento químico, eu sei que eu não vou comprar, mesmo se me der de graça. E você vai?". Aí o aluno falou assim: "Uai, se você não vai, eu não vou”. Aí ele quis saber o porquê. Sabe? Então é um negócio interessante.

Pesquisador: Olha que legal isso daí, você poderia escrever isso no grupo, né

O episódio 5 retrata o retorno da questão do "amassado das latas" como uma possível Questão Sociocientífica. Trata-se de um episódio bastante rico em aspectos que consideramos válidos no processo como um todo: argumentação sobre a fertilidade da questão, com a mobilização de elementos do campo dos conhecimentos específicos de química e questões de estratégias do campo da ciência e tecnologia na sociedade; registro de uma experiência em sala de aula contendo elementos de provocação, frutos dos conhecimentos mobilizados no PGP; participação do pesquisador como sustentador do processo formativo, com o incentivo da autoria e valorização de um dos papéis do PGP que é o de articular a relação teoria-prática.

Quanto à questão do "amassado das latas", como Questão Sociocientífica, o diálogo parte de um resgate do tema feito pelo pesquisador. O professor João traz novos conhecimentos específicos de química sobre a questão, porém a questão se amplia. $\mathrm{O}$ pesquisador, por sua vez, amplia as possibilidades de discussão quando foca o problema na questão das "embalagens dos alimentos" e não mais no "amassado das embalagens metálicas". Quando o pesquisador alarga o problema, abre a possibilidade para a percepção de outros aspectos da questão, como a utilização de novos produtos para embalar alimentos e a problemática envolvida, a tecnologia envolvida na produção de polímeros, a controvérsia envolvida no uso do plástico, que oferece, por um lado, praticidade e estética, mas, por outro, é um material muito poluente e pode causar problemas de saúde (como, por exemplo, um recente problema provocado pela substância Bisfenol $\mathrm{A}$, presente nos plásticos de mamadeiras, bicos e chupetas, que culminou com a proibição da comercialização pelo Senado).

O professor Joaquim registrou uma experiência ocorrida em uma das suas aulas, na qual ele provoca o aluno a se posicionar sobre a questão da decisão sobre comprar ou não um produto cuja embalagem metálica esteja amassada. No contexto provocativo criado pelo professor Joaquim, ele elenca a problemática do custo-benefício para o aluno se posicionar. Trata-se de uma rápida experiência com QSC em sala, mas representa empenho e interesse do professor na questão, especialmente quando ele a qualifica como "interessante". É nítido que quando o professor toma partido em uma situação problemática, as possibilidades de 
exploração da controvérsia se reduzem drasticamente, por conta do poder da opinião do professor, o posicionamento daquele que "sabe mais".

O pesquisador, aproveitando o depoimento da experiência do professor Joaquim, incentiva-o a escrever sobre esse momento da sua prática e trazer para o grupo para ser discutido na coletividade. Esse movimento de escrever, de assumir uma autoria e personalizar o que se faz, bem como o de significação e racionalização em grupo, são aspectos desejáveis para justificar e validar o nosso trabalho. A prática deve resgatar o seu significado e ser fonte de conhecimento (PUCCI, 1994). É importante a racionalização de uma experiência, que também expressa criatividade e envolvimento, em um processo que se baseia em pressupostos críticos, especialmente em Adorno e Horkheimer (1985), que valorizam o uso da Razão com ideais emancipatórios (PUCCI, 1994), bem como o resgate de espaço de criação, problematização e espontaneidade.

Elementos evidenciados: Já é apresentado um bom posicionamento sobre a fertilidade do tema, revelando posicionamentos que incluem conhecimentos específicos sobre a controvérsia em questão e ampliação da problemática para um contexto maior em busca de mais possibilidades. Há também registro de uma experiência em sala de aula, contendo elementos de provocação e estímulo à construção de posicionamento. A questão é deixada como uma possibilidade.

\section{Episódio 6: Problemáticas do tratamento das QSC em sala de aula}

Pesquisador: Então, por exemplo: "Eu quero trabalhar a questão do amassado de lata"... "do formol", que seja. Do formol! Se eu pegar e trouxer: "Gente, o formol é isso. É um composto formado por isso, isso e isso. Ele é uma substância tóxica e o que vocês acham? De usar ou não?”. Vocês acham que isso é frutífero? Vai sair alguma discussão?

Joaquim: Não.

João: Como, eu não entendi?

Pesquisador: Por exemplo, você chega lá na sala e vai trabalhar com a questão do formol. Você chega lá e diz assim: "Pessoal, é o seguinte... então o formol é isso e isso. É um composto químico baseado nessa equação aqui. Ele é tóxico. O que vocês acham, ele deve ou não ser usado no cabelo pra beleza?”. A minha pergunta é a seguinte: Esse tipo de abordagem, ela é uma abordagem que vai despertar no aluno a vontade de se posicionar?

[alguma expressão negativa] 
Pesquisador: O que falta nela, então?

Joaquim: Polêmica?

Pesquisador: Polêmica. Falta controvérsia. Quer dizer, eu sei que ele é tóxico, mas e daí? A pessoa pode falar assim: "Ah professor, mas a televisão fala que um monte de coisa é tóxico e a gente está comendo e não morre!”. Você vai dizer o quê? "Realmente, um monte de coisa tóxica e você está comendo tudo isso e não morre". Então como que a gente vai buscar essa questão controversa aí? Como a gente vai construir um contexto no qual as pessoas vão ter que se posicionar? Entende que esse que é o desafio?

João: Tem que tomar um conhecimento... de onde que surgiu...

O episódio 6 não trata de diálogos sobre se uma determinada questão é frutífera como Questão Sociocientífica. Trata-se de uma reflexão e provocação sobre o tratamento destas questões no contexto escolar. O pesquisador dá um exemplo de abordagem em sala de aula, cuja possibilidade de diálogo se reduz ao "sim ou não". Apresentado essa situação hipotética, o pesquisador conduz os professores a avaliá-la. O professor João, inicialmente, não compreende o sentido da provocação, o que demanda ao pesquisador uma reelaboração da questão. A nova situação tem o mesmo caráter de redutora de possibilidades de discussão, mas o problema proposto já é direcionado à questão do posicionamento. O professor Joaquim, por sua vez, reconhece que um contexto de construção de posicionamento requer polêmica, controvérsia, situação de múltiplas perspectivas. Por fim, o pesquisador apresenta outra situação que ilustra a pobreza de uma possível resposta de um aluno e insere questões que se convertem como desafios para um grupo que quer trabalhar com questões sociocientíficas, especial, a questão de construção de um contexto de provocação, argumentação e construção de posicionamento.

Ratcliffe e Grace (2003), Khishfe (2012) e Eastwood et al.(2012) reconhecem que a pluralidade de respostas, a multiplicidade de pontos de vista, a formação de opinião, a incompletude das questões, fazem parte de um contexto de um contexto de Educação Científica. Uma questão fechada ou já fortemente direcionada reduz severamente as possibilidades de, por exemplo, explorar os conhecimentos dos alunos, as opiniões espontâneas, e compreender a própria natureza do empreendimento científico que é passível de julgo, exame, contestação e diferentes pontos de vista. 
Elementos evidenciados: Estabelece-se um momento de reflexões sobre teoria e as possibilidades de prática, contendo diálogos sobre os desafios da prática com Questões Sociocientíficas.

Episódio 7: O suicídio como um problema real e como possibilidade de uma QSC

João: Aqui em Paranaíba seria interessante trabalhar... Fazer uma pesquisa, não sei... O que leva a pessoa ao suicídio. Seria interessante. Tem um alto índice de suicídios aqui em Paranaíba. Tem muitos e muitos mesmo que a gente nem fica sabendo.

Joaquim: É verdade. Teve uma época até que...

João: Não, está até proibido de anunciar. Não anuncia mais quando é suicídio. Sabe... Só fala que morreu e não fala o motivo. Aí eu cortando o cabelo ali e eles falando que uns três ou quatro tentaram e não conseguiram. Está muito mesmo.

Pesquisador: Então, mas...

João: Então teria que trabalhar, então, o que leva a pessoa a...

Joaquim: Isso daí é um problema social, né?

Pesquisador: É um problema social. É importante. Mas onde está o viés científico disso? Em termos de Ciência e Tecnologia... Não sei. Talvez esteja envolvido com algum tipo de alimento que é muito comum na região... Que está provocando alguma química no cérebro...

João: A água, talvez.

Pesquisador: A água.

Joaquim: É uma coisa interessante, né?

Pesquisador: Porque, inicialmente, não é uma Questão Sociocientífica. Porque tem o "sócio", mas não tem o "científico". Entendeu? Inicialmente. De primeiro encontro ela não é uma Questão Sociocientífica, é um problema social, importante, deve ser debatido, mas parece que não é nesse foco... Mas pode ser. Uma Questão Sociocientífica não vem pronta assim. A lata amassada, ela não vem pronta. Você tem que pensar: "Poxa, mas a lata amassada tem uma coisa interessante, né...”. A questão do suicídio, ela é de cara um problema social... de cara um problema psicossocial.

$$
[\ldots]
$$

Joaquim: Estou tendo uma ideia aqui, não sei se tem a ver. Se relaciona com a Ciência no aspecto de que vai ter que estudar a química do cérebro... as reações... Tentar entender se tem alguma atividade... Atividades fisicas que reduzem ansiedade, estresse... que vai mudar a qualidade de vida... Se algum tipo de alimento que ele come vai produzir substâncias no corpo que vai dar sensação de prazer...

Pesquisador: Entendi. 
Joaquim: Entendeu. Eu pensei nesse sentido de a Ciência entrar na questão do suicídio. Entender a química ou a física envolvida e...

Pesquisador: Então... bacana.

Joaquim: Buscar alternativas que busquem o prazer. Entendeu? Que não venha a entrar em tristeza... ou até assim, na questão do suicídio, tentar diferenciar o que é tristeza e depressão. Que tristeza é mais comum, mas depressão...

Pesquisador: Olha, Joaquim, essa é outra perspectiva do suicídio. Quer dizer, o objeto...

Joaquim: Que nem, por exemplo, ele sai daqui que tem uma grande incidência de suicídio e vai pra outro local. Mas ele sabe que... devido ao estudo do suicídio, ele sabe que, ele tem que realizar atividades físicas, realizar atividades cerebrais, exercitar a mente, fazer algum tipo de coisa para ter uma saúde mental boa. Dependendo do local onde ele vai estar, se houver suicídio, ele sabe, pelo estudo de suicídio, que tem que desenvolver uma saúde mental. Pensei nisso.

Pesquisador: Entendi. Ainda não é uma Questão Sociocientífica pelo seguinte: o objeto, suicídio, ele não está ligado com Ciência e Tecnologia, de início. Certo? Mas isso é uma possibilidade muito boa de trabalho. Eu não sei ainda se isso pode se converter em uma Questão Sociocientífica. Tem que sentar e pensar, mas por enquanto, ainda não me parece uma Questão Sociocientífica. Me parece ainda que a questão tecnológica, cientifica, está meio mascarada... Está mais em uma questão de como você vai atacar o problema do que o problema em si. Entendeu? Ele não é um problema provocado pela ciência, mas você vai usar a ciência pra entender. Então tem que pensar nessa questão... fica, então, pra amadurecer a ideia.

Como fruto de um processo que preza pelo desvelamento da realidade, reflexões sobre o contexto e sistematização de prováveis Questões Sociocientíficas mais férteis, surge, no episódio 7, o tema do suicídio. A questão surge por estar muito afeta à realidade dos envolvidos e se caracterizar como um problema a ser resolvido. Provavelmente, o apego em alguns aspectos de uma Questão Sociocientífica como ser um problema local, de ampla veiculação, abranger aspectos sociais, tenha levado o professor João a propor o tema e o professor Joaquim a se agregar. Porém, deixou-se de lado, nas justificativas, o aspecto científico da questão, bem como a controvérsia. Para Ratcliffe e Grace (2003), as Questões Sociocientíficas têm uma base na ciência e um impacto potencialmente grande na sociedade. Valorizar os elementos científicos e tecnológicos para possibilitar aprendizagem sobre a sua natureza é o que diferencia as Questões Sociocientíficas de uma questão social.

No episódio, o pesquisador rejeita insistentemente que o suicídio, tal como apresentado, possa se converter em uma Questão Sociocientífica, porém reconhece que pode surgir uma componente científica, caso se aprofunde na questão. Nos diálogos, o professor João participa trazendo elementos do contexto, no sentido de demonstrar a força do problema 
no município; o professor Joaquim e o pesquisador entram em uma discussão, com apresentação de argumentos e contra-argumentos sobre a validade da questão. O professor Joaquim, porém, procura justificar que haveria a possibilidade de "inserir" ciência ao atacar a questão do suicídio, mas não reconhece que o suicídio, a princípio, não é uma problemática que advém do campo cientifico ou tecnológico (mas pode vir) e nem as controvérsias presentes na questão.

Em um dos trechos de fala, o pesquisador comete falhas ao exemplificar a infertilidade do suicídio se remetendo à questão de não ser algo que se depare em qualquer lugar. O que soa paradoxal diante da valorização de problemas locais. O que ocorre aqui é a necessidade de deixar claro que a problemática local é incentivada por conta dos referenciais teóricos de Questões Sociocientíficas, bem como da perspectiva crítica, de desvelamento da realidade concreta. Contudo, essa problemática só é frutífera, no sentido da educação científica, se nela estiver contidos elementos da Ciência e da Tecnologia, pois parte-se da consideração de que a sociedade de modo geral é fortemente envolvida com esses elementos. Logo, os conhecimentos mobilizados para tratar de uma Questão Sociocientífica fazem parte da formação do cidadão que poderá mobilizar os mesmos conhecimentos, os princípios básicos, a prática argumentativa, o julgamento da posição de especialistas, a ponderação de questões de valores, por exemplo, com outras questões e em outros espaços.

Elementos evidenciados: Posicionamento pouco fundamentado sobre a fertilidade do tema, pois os posicionamentos se mostram carentes em compreensões mais aprofundadas sobre a natureza da Questão Sociocientífica. Estabeleceu-se, porém, uma situação de argumentação com elementos prós e contras. Apesar da precipitação do pesquisador, em vetar a ideia do suicídio antes de maiores aprofundamentos do grupo, a questão deixada como uma possibilidade.

\section{Episódio 8:}

Definição da QSC "Procedimentos Químicos para o alisamento capilar, especialmente oformol”

Pesquisador: Você quer falar do seu texto, João?

João: Acho que eu entendi errado... Sabe o que eu coloquei? Eu pensei que era pra colocar um assunto que eu queria trabalhar. Aí eu pensei no formol... Aí eu coloquei assim: "Durante o decorrer dos encontros, vários assuntos e temas de interesse comum foram analisados. $O$ assunto que eu gostaria de trabalhar com os 
alunos sobre esse problema é o uso excessivo do formol, pois todos os alunos têm conhecimento do uso dessa substância, principalmente as meninas que se preocupam com sua estética e que acham que o padrão de beleza é ter o cabelo liso". Aí eu achei que esse assunto era interessante de trabalhar com ele, porque eu poderia trabalhar a concentração de formol, a fórmula química dele, e vários outros aspectos sobre esse tema. Por exemplo, você pode usar 0,2\%, só que 0,2\% não alisa. 0,2\% é o que vem lá no xampu... Entendeu? Então não alisa. Por que se pode usar só 0,2\% sendo que não alisa? Eu até estava lendo um texto que passou no [programa de TV de ampla abrangência]... até o cabeleireiro mesmo, pelo próprio cheiro, reconhece a porcentagem, se tem muito ou pouco formol. Então eu acho que seria um aspecto...

Pesquisador: Em que você acha que isso pode se desdobrar... em mais coisas, por exemplo?

João: Então, sobre o que ele... Por exemplo, o perigo que ele nos traz, o câncer, queimadura... Não é que eu passei hoje e vou lá fazer um exame de câncer e vou ter. É em longo prazo. Entre 10 a 15 anos.

Pesquisador: A questão da indústria da beleza, também...

Maria: Eu tive um problema porque eu estive no salão e falei pra ela [a cabeleireira] "vamos fazer hidratação. Não é pra alisar! Meu cabelo já é liso. É naturalmente liso"... "Não é só pra tirar o ressecado". Tudo bem. E ela não falou que tinha concentração de acetato. Eu sou alérgica a acetato. Eu acho que além do acetato, tinha formol. Só que a reação apareceu 48 horas depois. E na embalagem dizia assim... ela não fez o teste... "se fizesse o teste, esperava 24 horas pra poder passar o produto". Se ela tivesse feito o teste e esperado 24 horas..

Pesquisador: Não ia acontecer nada.

Maria: Não tinha reação nenhuma. Só apareceu 48 depois.

Pesquisador: Estava no produto essa "24 horas"?

Maria: Mesmo assim...

Pesquisador: Não, eu digo assim... Onde estava escrito esse negócio de 24 horas?

Maria: Geralmente todos os produtos pedem que façam o teste, espera 24 horas... Eu tive uma reação alérgica...

Pesquisador: Seria alguma opinião científica... deve ser...

Maria: Sim. Todos esses produtos que vêm... Minha irmã é negra e ela tem o cabelo... e ela usa tudo que é coisa que alisa... e vira e mexe o cabelo dela está caindo... Então diz assim: "Passa e espera 24 horas", na indicação do rótulo. Às vezes 24 horas depende do organismo que vai reagir... tem organismo que demora mais. Outro ponto também, pegando um gancho dele, que a gente poderia trabalhar dentro de história é a noção de beleza ao longo da história. Por quê? Atualmente o cabelo... eu lembro que na época da minha formatura, em 90, teve uma festa, um coquetel, eu comprei um vidro de gel e fiquei meia hora embaixo do ventilador para o cabelo dar volume e ficar bem volumoso, porque o chique da época era o cabelo volumoso. E hoje não. Hoje é aquele cabelo que parece que jogou um balde de água na cabeça.

Pesquisador: É verdade. 
Maria: Então você pode pegar esse gancho e trabalhar, além da função do produto, qual é a influência que, ao longo da história, tem sobre o cabelo. Na década de 90, ninguém nunca pensava em passar formol no cabelo. Eles faziam... como é que fala.. esqueci o nome... pra cabelo cacheado.

Prof. Univ.2: Permanente.

Maria: Permanente! Esses dias chegaram o salão e disseram "eи quero fazer um permanente no cabelo"... “mas isso não se faz mais”... "mas eu quero!”.

Pesquisador: Por exemplo, como a gente tem que pensar no papel da ciência e da tecnologia, isso é um produto da ciência. Certo? Formol é um produto da ciência e que tem interesse econômico, porque quando existe uma demanda social... existe demanda social por alguma coisa que alisa o cabelo porque é uma corrida da beleza, digamos. Tem gente que chama de ditadura da beleza. E, por outro lado, existem os laboratórios de produção de cosméticos e tal que precisam dar conta dessa demanda e eles querem dar conta porque eles querem ganhar dinheiro. E então a gente começa a pensar no papel dessa ciência, como ela vai convencer que uma dosagem de formol não faz mal? Por exemplo, "ciência fala que 0,2\% na solução não faz mal". Não faz mal em todo o organismo humano, por exemplo? 0,2\% tem uma margem de erro? Como isso é calculado? Existem outras opiniões que o formol, qualquer quantidade mínima que por, faz mal? Pode ser que exista. Entende que temos que começar a refletir sobre a ciência, também? Como que essa ciência está fazendo parte da sociedade fortemente. Por trás do formol existe toda uma relação entre ciência e sociedade que precisa ser considerada. Entende?

Maria: Toda a atenção dos laboratórios está em cima da mídia e da sociedade. Eles impõem um padrão de beleza com interesse de vender produto.

Pesquisador: Mas João, eu por aí também. A questão do formol foi estudada mesmo... entre um dos... inclusive foi você que propôs, também. E eu acho que a gente pode deixar como um potencial tratamento. Uma Questão Sociocientífica em potencial. Porque a gente sabe que as pessoas realmente estão usando muito. As meninas, especialmente. Mas tem também os meninos que estão usando por conta de jogador de futebol que usa e os meninos estão usando também esses alisamentos pra fazer moicano, que é um estilo... Que é questão de beleza também... Questão de moda... Questão de tendência... Questão de influência do futebol. Isso pode se desdobrar em muita coisa. Isso que eu quero dizer, que é uma questão frutífera.

Graduando: Tem a questão da precocidade, também.

Pesquisador: As meninas começam mais cedo, né?

Graduando: Antes você via só mulheres que pintavam o cabelo, faziam esse tipo de coisa. Agora você já vê cada vez mais precoce.

Joaquim: É verdade.

Pesquisador: Isso pode afetar o organismo.

João: Você vê essas meninas do Ensino Médio, de catorze anos, tudo com os cabelos lisos, pintados.

Maria: Eu conheço criança de onze anos que já fez alisamento.

Pesquisador: Já fez o quê? 
Maria: Já fez alisamento.

Pesquisador: De onze anos? E é engraçado também... O que isso significa em termos de etnia, né? Porque o cabelo encaracolado ou crespo vem dos negros... Então, isso significa alguma coisa em termos de beleza e etnia? Então tem essa questão de etnia também. De repente é uma questão de racismo não superado, velado.. Não sei. Pode ser que tenha pessoas falando sobre isso. Porque o cabelo liso é um cabelo geralmente de pessoas brancas e etc... o que isso significa em termos de estética? Estética, racismo, etnias... O que isso pode significar? Talvez não tenha sentido, mas talvez tenha. É outro tipo de raciocínio que também pode ser discutido.

Joaquim: Tem sentido. Tem a questão de aceitação no grupo, né? Sei lá... Todo mundo está fazendo, né? Então para sentir bem, eu vou e faço também.

Maria: Eu já em alguns artigos sobre isso... que o lugar onde a predominância é negros, eles aceitam melhor o cabelo cacheado, o lugar onde a predominância é branco, o cabelo cacheado não é tão aceitável.

Pesquisador: E aí quem é negro nesse espaço está alisando os cabelos?

Maria: Passa a alisar o cabelo.

Pesquisador: Como se fosse mudar a etnia porque o cabelo alisou.

Maria: Como se "o fato de eu ter cabelo liso, eu não sou negra".

Pesquisador: Ou "eu estou mais bonito”, por exemplo. A ideia de beleza... Estética.

Maria: A ideia de estética e de autoafirmação.

Prof. Univ.2: E olha que não é só isso. A questão da aceitação do grupo... Você é mais aceito no grupo quando você se parece com o grupo. Não é verdade?

Este é um dos pontos altos do desenvolvimento do PGP: a definição da Questão Sociocientífica do grupo. O episódio 8 apresenta uma situação de diálogo que compreende uma diversidade de sujeitos muito importante e provavelmente decisiva na aceitação conjunta do tema como a Questão Sociocientífica elencada pelo grupo.

Desde o mês de maio de 2012, a questão do formol paira sobre os diálogos no grupo. Depois da proposição do tema, o mesmo passa a surgir esporadicamente, seja durante as leituras e reflexões sobre os textos ou em um contexto de provocação direcionado. Em setembro, porém, a questão é definida. O processo, aparentemente acidental, não se configura assim. Durante a leitura de textos de significação do processo, o professor João fez a leitura de um texto redigido por ele sobre o que ele tinha interesse em trabalhar, tratando de Questões Sociocientíficas, mesmo que a ideia da elaboração do texto fosse outra. $\mathrm{O}$ pesquisador aproveita os elementos evidenciados pelo professor e provoca uma continuidade. Inicia-se, então, um movimento de agregação à ideia que produz um resultado muito interessante: $\mathrm{O}$ professor João, mobiliza conhecimentos específicos de químicas, mas avança quando também 
traz a questão dos riscos à saúde humana; a professora Maria mobiliza conhecimentos de experiência própria e, na medida em que o diálogo se desenvolve, ela também avança na proposição de elementos históricos, valores, interesses da ciência; o professor Joaquim participa timidamente, mas quando o faz é no sentido de complementação de alguma ideia; os membros da universidade, Prof. Univ.2 e Graduando, também participam timidamente, com a proposição de elementos ou complementação de ideias; o pesquisador inicia o processo como problematizador e sustenta a problematização acrescentando elementos da Ciência e da Tecnologia e enfatizando a importância da discussão destes elementos.

Observa-se neste último episódio, o que chamamos de polifonia. O sentido aqui valorizado é o de que todos os participantes estão envolvidos no momento de fala, trazendo elementos da sua área de formação, mobilizando conhecimentos adquiridos ao longo da sua história, representando com propriedade o local de onde fala (Universidade ou Escola).

Os elementos trazidos neste episódio são mais fundamentados, consistentes, o que sugere um trânsito maior pela teoria. Já no episódio, podemos apontar alguns aspectos evidenciados: Conhecimentos específicos, especialmente de química; questão de valores e comportamentos, como padrões de beleza, estética, questões étnicas, racismo, precocidade; resgate de uma experiência relacionada ao assunto, com foco nos malefícios e danos à saúde; proposta de tratamento em sala de aula pela via da história do uso do produto; Questionamentos sobre a Natureza da Ciência, como o interesse econômico envolvido, o poder creditado à ciência resultando no fato de ela dar a palavra final nas situações.

Em uma visada teórica, temos uma série de elementos que depõem a favor da riqueza do tema: Alinhando-se com Ratcliffe e Grace (2003), o tema envolve formação de opinião e realização de escolha no nível social e pessoal, é frequentemente reportado na mídia, lida com informações incompletas (como o relatório da ANVISA sobre a proibição, que implica no questionamento sobre quem faz os testes para a ANVISA, quais os procedimentos adotados para viabilizar a proibição, entre outros), abrange uma dimensão nacional, com forte manifestação local; envolve análise de custo-benefício; envolve valores e raciocínio ético (o que também se alinha com (GUIMARÃES, 2011; RATCLIFFE e GRACE, 2003; ZEIDLER e KEEFER, 2003; GRAY e BRYCE, 2006)); pode exigir alguma compreensão de probabilidade e risco. Além de requerer incursão em aspectos jurídicos, de legislação, e compreensão aprofundada da Natureza da Ciência e da Tecnologia, para fundamentar a questão do interesse, associação com a mídia, influência na vida social, desenvolvimento de uma tecnologia perigosa, porém rentável, entre outros. 
Entendendo que havia um consenso em adotar essa questão como a Questão Sociocientífica, os esforços centraram no aprofundamento da questão. Cada participante fez uma pesquisa individual buscando elementos novos, questões importantes a serem compreendidas pelo grupo, pois era entendido que antes de iniciar um trabalho em sala de aula e sustentar situações de diálogo, o grupo precisaria estar entendendo muito bem a questão. Essas decisões fazem parte do processo formativo: pesquisa, reconhecimento das limitações, planejamento, organização, entre outros.

\section{CONSIDERAÇÕES}

O processo de constituição da QSC do grupo revela o valor dos diálogos, dos conhecimentos diversos mobilizados, da argumentação bem fundamentada, bem como destaca o papel do pesquisador como provocador e os professores como participantes ativos e que se posicionam. O envolvimento dos sujeitos é gradual, depende do quanto o assunto afeta cada um, o que ilustra, em medida semelhante, um processo dentro da sala de aula: quanto mais o aluno se reconhecer como participante do objeto de discussão, quanto mais for provocado a se posicionar e emitir opiniões em contextos argumentativos, tanto mais vai se alcançando um cenário educacional de formação cidadã e envolvimento dos alunos. No caso dos professores, o processo permite a mobilização de conhecimentos tradicionais, da própria cultura, e a articulação destes com conhecimentos científicos, a possibilidade de trabalho nas mais diversas áreas do conhecimento (interdisciplinaridade), por conta da pluralidade de elementos mobilizados por uma controvérsia sociocientífica, a construção de espaços de fala e de posicionamentos, que permite o estreitamento da ponte teoria-prática e efetiva uma práxis profissional que perpassa ao professor que reflete sobre a própria prática, mas abre portas para o professor que constrói, que problematiza, que transita entre campos teóricos e práticas, o professor crítico.

\section{BIBLIOGRAFIA}

ADORNO, T. W. Notas Marginais sobre Teoria e Práxis. A Dialéctica do Esclarecimento e outros textos de Theodor W. Adorno, 2001. Disponivel em: <http://adorno.planetaclix.pt/tadorno1.htm>. Acesso em: 02 Junho 2012. 
ADORNO, T. W.; HORKHEIMER, M. Dialética do esclarecimento. Tradução de Guido Antônio de Almeida. Rio de Janeiro: Jorge Zahar Editor, 1985.

BARDIN, L. Análise de Conteúdo. Tradução de Luís Antero Reto e Augusto Pinheiro. 4a . ed. Lisboa: Edições 70, 2009.

BOGDAN, R. C.; BIKLEN, S. K. Investigação qualitativa em Educação: uma introdução à teoria e aos métodos. Porto: Porto Editora, 1994. Coleção Ciências da Educação.

BRASIL. Lei no 9.394, de 20 de dezembro de 1996. Lei de Diretrizes e Bases da Educação Nacional, Brasília, 20 Dezembro 1996. Disponivel em: <http://www.planalto.gov.br/ccivil_03/Leis/L9394.htm>. Acesso em: 04 Setembro 2012.

BRASIL. Parâmetro Curriculares Nacionais: Ensino Médio. Brasília: SEB/MEC, 2000.

BRASIL. Orientações Educacionais Complementares aos Parâmetros Curriculares Nacionais. Brasília: SEB/MEC, 2002.

DÉSAUTELS, J.; LARROCHELLE, M.About the epistemological posture of science teachers. In: TIBERGHIEN, A.; JOSSEM, E. L.; BAROJAS, J. Connecting research in physics education with teacher education. [S.1.]: International Commission on Physics Education, 1997,1998.

EASTWOOD, J. L. et al. Contextualizing Nature of Science Instruction in Socioscientific Issues. InternationalJournalof Science Education, 2012. 1-27.

GALVÃO, C.; REIS, P.; FREIRE, S. A discussão de controvérsias sociocientíficas na formação de professores. Ciência\&Educação, Bauru, 17, n. 3, 2011. 505-522.

GRAY, D. S.; BRYCE, T. Socio-scientific issues in science education: implications for the professional development of teachers. Cambridge JournalofEducation, Londres, 36, n. 2, Junho 2006. 171-192.

GUIMARÃES, M. A. Raciocínio informal e a discussão de questões sociocientíficas: o exemplo das células-tronco humanas. Faculdade de Ciências - UNESP. Bauru, p. 220. 2011. Tese de Doutoramento.

HILÁRIO, T.; REIS, P. G. R. Potencialidades e limitações de sessões de discussão de controvérsias sociocientíficas como contributo para a literacia científica. REU, Sorocaba, v. 35, n. 2, p. 167-183, Dezembro 2009.

HODSON, D. Toward a philosophically more valid science curriculum. Science Education, 72, n. 1, 1988.19-40.

HODSON, D. Looking to the future: building a curriculum for social activism. Rotterdam: Sense Publishers, 2011. 
KHISHFE, R. Nature of Science and Decision-Making. International Journal of Science Education, 34 , n. 1, 2012.67-100.

LOPES, N. C. Aspectos formativos da experiência com questões sociocientíficas no ensino de ciências sob uma perspectiva crítica. Faculdade de Ciências de Bauru - UNESP. Bauru, p. 230. 2010. Dissertação de Mestrado.

MAAR, W. L. Adorno, Semiformação e Educação. Educação e Sociedade, Campinas, 24, n. 83, Agosto 2003. 459-476.

PEDRETTI, E. G. et al. Promoting Issues-based STSE Perspectives in Science Teacher Education: Problems of Identity and Ideology. Science \&Education, 17, n. 8-9, 2008. 941-960.

PUCCI, B. Teoria Crítica e Educação. In: PUCCI, B. Teoria Crítica e Educação: A questão da formação cultural na Escola de Frankfurt. Petrópolis, RJ; São Carlos, SP: Vozes; EDUFISCAR, 1994. Ciências sociais da educação.

RATCLIFFE, M.; GRACE, M. Science Education for the citizenship: Teaching socio-scientific issues. Philadelphia: Open University Press, 2003.

REIS, P. G. R. Controvérsias sócio-científicas: discutir ou não discutir? Percursos da aprendizagem da disciplina de ciências da Terra e da Vida. Faculdade de Ciências da Universidade de Lisboa. Lisboa, p. 488. 2004. Tese de Doutoramento.

SANTOS, P.G.F. O tratamento de Questões Sociocientíficas em um grupo de professores e a natureza do processo formativo fundamentado em uma perspectiva crítica. Faculdade de Ciências de Bauru UNESP. Bauru, p. 209, 2013. Dissertação de Mestrado.

ZEIDLER, D. L.; KEEFER, M. The role of moral reasoning and the status of socioscientific issues in science education: phylosophical, psychological and pedagogical consideration. In: ZEIDLER, D. L. The role of moral reasoning on socioscientific issues and discourse in science education.Dordrecht: KluwerAcademicPublishers, 2003. p. 7-38. 